\title{
Estrategias documentales en la representación del hecho histórico.
}

\section{Estratégias documentais na representação de fatos históricos.}

Documentary strategies in the representation of historical events.

\author{
Rebeca Moreno Villarín \\ rebemv86@hotmail.com \\ Ex alumna Universitat de Barcelona. Master: Artes visuales y educación: Un enfoque cons- \\ truccionista
}

\section{RESUMEN}

Este artículo trata de visibilizar una serie de estrategias de representación de las prácticas documentales históricas y cómo estas son articuladas para generar discursos políticos e ideológicos a través de un análisis fílmico. Para ello he seleccionado tres documentales- Respite de Harun Farocki, El edificio de los chilenos de Macarena Aguiló y Vivir la Utopía de Juan A. Gamero- a partir de los cuales realizo un análisis del discurso. El motivo de mi elección es la posición desde la que el realizador muestra el hecho y cómo este se relaciona con él.

La investigación se centra en la producción del documental histórico y se realiza un análisis del discurso a través de los materiales que argumentan el film y del montaje de estos. Hace referencia a cómo se representa el hecho histórico desde la parcialidad de la imagen. Cómo se genera el discurso a través de dicha representación y del montaje del material que documenta el hecho dando lugar a espacios de de reflexión y construcción de significados, en relación con el espectador. Finalmente, se alude a la posición del realizador respecto al acontecimiento y a los intereses políticos e ideológicos del mismo.

Palabras clave: documental, estrategias de representación, montaje, discurso, imagen.

\section{RESUMO}

O presente artigo trata de dar visibilidade a diversas estratégias de representação nas práticas de documentários históricos e como se articulam para gerar discursos políticos e ideológicos, através de uma análise fílmica. Para tal fim, foram selecionados três documentários - Respite de Harun Farocki, El edificio de los chilenos de Macarena Aguiló e Vivir la Utopía de Juan A. Gamero - a partir dos quais realizo uma análise de discursos. O motivo da minha escolha é entender a posição do realizador que mostra o fato e como ele se relaciona com este.

A investigação centra-se na produção do documentário histórico e analisa o discurso através dos materiais que argumentam o filme e de sua montagem. Faz referência a como se representa o fato histórico levando em consideração a parcialidade da imagem - de que forma se gera o discurso através da representação 
e da montagem do material que documenta o fato, dando lugar a espaços de reflexão e construção de significados em relação com o espectador.

Finalmente, alude à posição do realizador em frente ao acontecimento e a seus interesses políticos e ideológicos.

Palabras chave: documentário, estratégias de representação, montagem, discurso, imagem.

\section{ABSTRACT}

This article attempts to make visible a group of representation strategies in the historical audiovisual production and how these are organized in order to generate political and ideological discourses by means of film analysis. For this purpose I have selected three documentaries -Respite by Harun Farocki, The Chilean Building by Macarena Aguiló and Living Utopia by Juan A. Gamero-, from which I analyse the discourse. The reason for my choice is the position from which the producer shows the fact and how he is related to this.

The research focuses on the production of the historical documentary and analyzes the discourse through the argument sources and trough the editing process. It refers to the way the historical fact is represented from the partiality of the image. How the discourse is generated trough said representation, trough the editing of the material which documents the fact, giving rise to spaces for reflection and to construction of meaning in connection with the audience. Finally, it alludes to the position of the producer with regard to the event and to his own political and ideological interests.

Keywords: documentary, representation strategy, editing, discourse, image 


\section{INTRODUCCIÓN}

Mediante este artículo de investigación me propongo plantear una serie de problemáticas en relación a la producción, del film documental, que tratan de responder a ¿Qué estrategias de representación se dan en las prácticas documentales? y ¿cómo se articulan para generar discursos políticos e ideológicos a partir de la representación histórica? Así pues, se examina la relevancia que toma el material a la hora de documentar el hecho, el uso de las imágenes y cómo se organizan dichos materiales creando espacios de reflexión, de no visión, apelando a la intertextualidad y generando conocimiento. Del mismo modo, se analiza la disposición de dicho material como generador de discursos políticos e ideológicos que desvelan a su vez el posicionamiento del realizador y la relación de este con los hechos y la forma de contarlos.

Los tres documentales elegidos y nombrados al inicio, tienen como telón de fondo momentos históricos claves. El motivo de mi elección es la perspectiva desde la que se narra el documental, desde lo cotidiano o individual del hecho, pasando por la subjetividad de la mirada del realizador y escapando de las abundantes representaciones históricas hegemónicas, objetivas supuestamente, a las que estamos acostumbrados y nos invitan a reflexionar sobre los hechos. Este modo de descripción evoluciona en el cine documental, conociéndose como "giro subjetivo", el cual supone un desplazamiento en la posición del autor, quien ya no describe el hecho histórico desde fuera, sino que se posiciona dentro de él y muestra no solo su visión sobre este, sino también su relación con este. Los tres documentales elegidos parten de lo cotidiano, no tratan de representar o reconstruir el hecho histórico en sí, sino que nos muestran las consecuencias y las experiencias que tienen lugar en paralelo a los acontecimientos, dándonos así una visión subjetiva intencionadamente y personal. Buscan una exigencia en la mirada del espectador, la reflexión, no sólo en lo relativo al tema que se desarrolla sino al cómo se desarrolla. Al mismo tiempo reclama un conocimiento implícito en el individuo que se relacione de forma intertextual con el documental y la capacidad de mirar más allá de lo visible para entender qué quiere decir el film o qué quiere que concibamos.
Como dice Brecht, hablando de cómo se entiende el realismo, "Todo aquel que no tiene prejuicios formales, sabe que la verdad puede encubrirse de muchas maneras y debe ser dicha de muchas maneras" (1984:239).

La motivación para realizar este artículo parte por un lado de la existencia de una posición pasiva del espectador, por lo que se procura problematizar dicho posicionamiento con el propósito de interpelar la "mirada" del mismo, visibilizando las estrategias fílmicas y la articulación de las mismas para generar discursos. Y por otro lado, por el sentido Ellsworth le da a la "experiencia del ver" (2005:35) basándose en el film como forma pedagógica.

Considero que este artículo puede ser de utilidad, teniendo en cuenta la importancia de la visualidad, la mirada y la direccionalidad fílmica en la construcción de conocimiento desde un punto de vista social, cultural y político. (Ellsworth, 2005; Rose, 2001; Sánchez de Serdio, 2010).

Visibilizar las estrategias de representación nos permite aproximarnos al film documental desde una posición activa en la producción de significados, forzar "a intercambiar la posición del espectador pasivo por las del investigador o experimentador científico que observa fenómenos e indaga sus causas" (Rancière, 2010:11,12) Escudriñando de este modo todo aquello que el film nos quiera transmitir implícita o explícitamente y profundizando en la construcción de conocimiento, a través del documental cabe la posibilidad de comprender el mundo y cómo nos relacionamos con él y en él.

En definitiva este artículo pretende sensibilizar al espectador ante la existencia de una serie de estrategias, que al ser obviadas lo posicionan como espectador pasivo, para que se produzca así "la emancipación del espectador" (Rancière, 2010:19)

Se debe tener en cuenta que este artículo profundiza en las políticas de representación del documental, por lo que la presencia del espectador estará mediada por el protagonismo de las estrategias documentales, aun así, del mismo modo que "No hay teatro sin espectador" (Rancière, 2010:10), esta investigación no tendría sentido sin referirnos a la mirada del espectador, aunque solo sea como mero 
receptor del tema que nos atañe, el documental. Es en último término, es el sujeto al que el film se dirige y del que se espera una acción de comprensión y de reflexividad ante él, teniendo presente la importancia de su mirada en la producción de significados.

\section{LA "PRUEBA" EN EL DOCUMENTAL/ARCHIVO VISUAL: LOS USOS DE LA IMAGEN}

Comenzaré el análisis a partir del uso de lo que Nichols denomina "prueba". Este se refiere a ella como el "material factual recogido para apoyar la argumentación" (Nichols, 1997:118).

Debemos dejar a un lado la idea del documental como constatación del mundo real, pues como bien dice Nichols "Ios documentales no presentan la verdad sino una verdad" (1997:161). Por lo tanto no muestran el mundo histórico sino una representación parcial del mismo, valiéndose de la construcción de una argumentación que da cuenta de esta visión particular del mundo, a través de materiales documentarios o lo que Nichols denomina "pruebas" que sustentan dicha argumentación y crean un vínculo con el mundo que representa. Estas "pruebas" se traducen en entrevistas, testigos, documentos, dibujos, fotografías que validan la existencia del mundo que describen.

Dentro de los materiales documentarios existe una estratificación, en la cual cobran mayor relevancia dos tipos de materiales: la imagen/archivo visual y la entrevista/testigo. Ambos son los protagonistas de debates interminables que hablan de la parcialidad de la imagen y que pretenden otorgarle mayor credibilidad a uno que al otro, sin embargo como Didi-Huberman dice, acerca de la memoria: “(...) una imagen acude allí donde parece fallar la palabra; a menudo una palabra acude allí donde parece fallar la imaginación" (2004:49).

En relación a la parcialidad de la imagen y los usos que se hacen de ella en el documental surge otra problemática, el discurso que el montaje de esta genera. John Tagg habla del papel de la fotografía en las prácticas documentales, la naturaleza de esta y la diversidad de técnicas y procedimientos que se articulan a partir de ella para extraer y evaluar la "verdad" en el discurso (Tagg, 2005). Tomaré el papel de la fotografía para aplicarlo más ampliamente a la imagen en general o archivo visual.

El archivo visual como constatación del mundo histórico al que nos referimos surge del uso de la imagen en el documental, en relación a los sistemas de poder y vigilancia como demostración de la realidad, como estrategia de efecto de verdad bajo el poder político y económico de una sociedad, como dice Tagg "Al igual que el estado la cámara no es neutral. Las representaciones que producen están sumamente codificadas y el poder que ejerce nunca es su propio poder" (Tagg, 2005:85). El archivo visual utilizado para Respite procede de la filmación realizada por Rudolf Breslauer, asesinado pocos meses después en Auschwitz en el que se muestra la "cotidianeidad", el trabajo y el día a día de los judíos en un campo de tránsito nazi, bajo encargo del comandante de las SS Albert Gemmeker, con fines propagandísticos. Este archivo no muestra a primera vista todo lo que sucede en un campo de trabajo, aquel que ejerce el "poder" trata de beneficiarse de la parcialidad de las imágenes, pero en su descontextualización podemos hallar ese momento de "verdad" del que habla Steyerl (Steyerl, 2009)

Farocki hace una reinterpretación de las imágenes a través de varios textos intercalados y el montaje de las mismas. Nos invita a ver lo que hay detrás de las imágenes que se muestran, a generar significados y a vislumbrar diferentes discursos dependiendo de la insistencia de la mirada.

Por el mismo motivo, el de comprender las imágenes, en Respite estas se repiten varias veces, no para constatar el discurso de las imágenes, sino para dar la posibilidad de una relectura de las mismas, según dice Farocki: "no puedes comprender nada en una primera lectura" (2009). Un ejemplo de ello es la imagen de una mujer en silla de ruedas, la cual se repite en varias ocasiones con diferentes textos; el primero no habla de ella: "The boxcars and cattle cars went to Auschwitz", después se refiere a su maleta: On the woman's suitcase is an address" (figura 1).Dicha repetición establece una relación entre la mujer y la maleta, en la que Farocki amplia la imagen para mostrar una fecha (figura 2) y la última vez que aparece esta secuencia (figura 3), el autor desvela el destino que esperábamos: "She was deported on 
May 19, 1944 to Auschwitz and murdered right after arriving" (figura 4)

Otros de los usos que Farocki hace de las imágenes en el montaje para que se preste atención a ellas, es ralentizar la secuencia, congelar escenas o remitirnos a otras. El autor justifica las repeticiones de las imágenes diciendo: "Tienes que comprender las circunstancias, quien lo ha filmado, con qué intenciones..." (Farocki, 2009). Esta idea no sólo justifica las repeticiones sino los textos, las ampliaciones y las imágenes congeladas; en definitiva, el montaje en sí.

De este modo en Respite tenemos por un lado, esa huella visible con un discurso implícito, que Farocki reinterpreta hacia el final del film cuando un texto dice: "The images were supposed to say: don't close the camp don't deport the workers!". Este parece hallar, en el film de Breslawer, un acto de resistencia a través de las imágenes, a fin de demostrar la utilidad, dedicación y autosuficiencia de los judíos; un ruego de mantener abierto el campo Westerbok, un ruego a vivir, una resistencia a la muerte. Por otro lado, los comentarios de los textos que interrogan a las imágenes y la reordenación de estas, no sólo le dan un nuevo sentido al discurso, sino que además Farocki es capaz de mostrar en ellas hasta el más mínimo detalle y darnos a conocer un minucioso trabajo de investigación.

Finalmente, retomando la mirada del espectador y el documental como lugar de reflexión y construcción de conocimiento, es importante destacar en Respite el fuera de campo que se da en este film como un espacio de no representación, con el objetivo de descolocar al espectador de su posición pasiva - voyeur ante la representación, a una posición de inquietud, donde construir significados- (Marrero, 2008; Sánchez de Serdio, 2010). Exige un esfuerzo por parte del espectador, el ver más allá de lo que el realizador muestra. Rose da una gran importancia al fuera de campo a la hora de analizar el discurso diciendo: "discourse analysis also involves reading for what is not seen or said. Absences can be productive as explicit naming; invisibility can have just as powerful effect visibility". (Rose 2001:157).

En Respite, las imágenes que se muestran no generarían la misma cantidad de significados sin los textos y sin el esfuerzo del espectador por imaginar, por ver aquello que no se representa en las imágenes, por generar relaciones con lo que ya conoce.

Respite no muestra "todo", sin embargo, sí puede ser entendido como "parte" de esa realidad más compleja y en función de los usos que se hagan de ella, será capaz de generar unos u otros discursos políticos e ideológicos, de construir un conocimiento acerca de los mismos. Esta construcción hace que la "experiencia de ver" sea relacional, que conecte con el "yo", entre otros conocimientos, otras miradas y el poder (Ellsworth, 2005). El documental como representación de una parte de la realidad es capaz de activar el sentido relacional de la "mirada" y generar así significados a partir de lo que vemos y conocemos.

\section{EL DISCURSO DOCUMENTAL A PARTIR DEL MONTAJE QUE DOCUMENTA EL HECHO:}

El montaje es la disposición del material documentario/ pruebas de forma estratégica en la representación. Sirve para argumentar el discurso que se quiere transmitir. De esta manera la articulación de este material, junto a una serie de elementos, definirá el sentido del discurso. Steyerl, refiriéndose al montaje del documental que representa las protestas de los trabajadores, dice:

Cada articulación es un montaje de diversos elementos- voces, imágenes, colores, pasiones o dogmas- dentro de cierto periodo de tiempo y con cierta extensión espacial. La importancia de los momentos articulados depende de eso. Sólo tienen sentido dentro de esa articulación, según su posición (2005:1).

Estos elementos tienen además una función persuasiva que se constituye a través de la disposición que toman. Dicha función es denominada, tanto por Nichols como por Van Dijk, "Retórica”, el primero la define como "un medio a través del que el autor intenta transmitir su punto de vista de un modo persuasivo" (Nichols, 1997:182). Van Dijk dice que su función "es convencer a otros de la veracidad o aceptabilidad de lo que uno dice" (2003:307). Ambos hacen referencia a los escritos sobre argumentación aristotélica refiriéndose a la retórica como "prueba artística", la cual deja de ser un medio para convertirse en estrategia. Estas estrategias 
son analizadas desde tres posiciones: la ética, la emoción y la demostración y su función es persuadir al espectador en beneficio del autor. Mediante el montaje de estas se genera el discurso documental.

Vivir la utopía es un buen ejemplo de la articulación de elementos de los que habla Steyerl, con el fin de generar un discurso claramente ideológico. En el documental se muestra una serie de elementos de índole anarquista o liberal, tales como símbolos de la CNT-FAI, el himno Republicano y Anarquista, publicaciones de revista, entre otros. Estos se articulan en el montaje y a través de una continua repetición ${ }^{1}$, apoyan la ideología del discurso documental. Al mismo tiempo cumplen una función "demostrativa" ${ }^{2}$, tratan de demostrar esa realidad, en este caso, además, conllevan una ideología explicita y unos ideales insertos en el simbolismo.

El montaje sigue una estructura cronológica, alternando las entrevistas generando una agrupación temática a través de la voz en off. Primero presenta las bases teóricas del anarquismo y posteriormente el desarrollo de los hechos finalizando con el fracaso de la II República. Los temas que se desarrollan en las entrevistas son la educación, la familia, la cultura, las experiencias y la derrota. Las etapas de esplendor del movimiento quedan reafirmadas por las imágenes victoriosas fundidas con los himnos. El discurso ideológico toma una perspectiva emocional ${ }^{3}$ persuasiva debido a lo explicito del argumento. El uso de los materiales busca una base moral común entre discurso y espectador apelando a la emotividad en tanto que este se siente identificado ideológicamente con el discurso. Hacia el final del documental, la disposición de los materiales toma una perspectiva dra

\footnotetext{
${ }^{1}$ Repetición como figura retórica es utilizada de forma estratégica de representación, las respaldan y reiteran implícitamente el discurso del documental.

2 Las pruebas demostrativas, sirven como ejemplo, no son demostrativas en el sentido de "prueba" como muestra, sino que han de ser ante todo persuasivas, independientemente de su objetividad.

3 Las pruebas artísticas emocionales hace referencia a la yuxtaposición de imágenes y sonidos que apelan a la emotividad del público. Esta yuxtaposición genera un discurso moral, que parte de la idea de que el realizador y el espectador poseen una base moral común
}

mática y melancólica para representar la derrota; las escenas que aparecen son de retirada, de fábricas derribadas, fusionadas con una marcha fúnebre, mientras se suceden imágenes de los cadáveres de los fusilamientos que acontecen el final. El desenlace otorga la culpabilidad moral a aquellos opuestos al discurso ideológico.

Al visionar estas pruebas/materiales desde una perspectiva ética ${ }^{4}$, se puede entrever el posicionamiento del realizador. Esto se visibiliza aun más en que las referencias del otro bando son mínimas, lo cual hace dudar de la objetividad que trata de mostrar la voz en off. Si comparamos el discurso político e ideológico "la presentación positiva que hace en sí mismo el orador se combina con la presentación negativa del otro o de los otros" (Van Dijk, 334:2009). Encontramos comentarios que apuntan la violencia del anarquismo, pero quedan contextualizados, representados y condenan dicha violencia de forma que la desvinculan de los ideales de colectividad que el documental valora. La presencia negativa del otro bando queda implícita en algunos comentarios de la voz en off como: "los rebeldes asesinan allí por donde avanzan a simpatizantes y militantes republicanos y de izquierda, en la España leal a la república, las represalias no se hacen esperar para todo aquel sospechoso de apoyar a los rebeldes".

El conocimiento sobre el momento histórico, propio del documental expositivo, tiene un carácter epistemológico que Nichols lo designa, parafraseando a Foucault como:

Esas formas de certeza interpersonal que están en conformidad con las categorías y conceptos que se aceptan en un tiempo y lugar específicos o con una ideología dominante del sentido común como la que sostienen nuestros propios discursos de sobriedad (Nichols, 1997:69).

Estos discursos están inscritos en la unidireccionalidad de las entrevistas en las que todos los participantes poseen una

\footnotetext{
4 Las pruebas éticas hacen referencia al tratamiento objetivo e imparcial del tema, o al menos el narrador debe dar esa impresión, para mayor credibilidad.
} 
misma ideología y en la desigualdad de exposición de archivos visuales de los "rebeldes". Es finalmente un documental que da voz a los protagonistas de un movimiento que las historias hegemónicas han pasado por alto. Lo cual resulta contradictorio, pues la forma en la que se constituye este film se asemeja precisamente a las representaciones de dichas historias, al negar la posibilidad de otros puntos de vista externos al movimiento.

Del mismo modo que Foucault muestra la existencia de unos regímenes de la verdad socialmente aceptados, los discursos históricos -representaciones, interpretaciones y conocimientos sobre los hechos- constituyen la "historia" socialmente aceptada como verdadera u oficial. John Tagg, basándose en Foucault, habla de estos sistemas que producen y difunden esta verdad socialmente aceptada diciendo:

Debemos olvidar los argumentos de una desacreditación documental de lucha "por" la "verdad" o "a favor" de la "verdad", para ver que se trata de una batalla que se debe dirigir hacia las normas, operativas en nuestra sociedad, según las cuales las representaciones "verdaderas" y "falsas" están separadas. Es una batalla que se libra contra las instituciones que tienen en nuestra sociedad el privilegio y el poder para producir y transmitir un discurso verdadero (Tagg, 2005:123).

Como ya mencioné anteriormente como motivo de la elección de los documentales, estos tratan de distanciarse de la dicotomía de representaciones "verdaderas" y "falsas", mostrando otros relatos, experiencias que lo que realmente buscan es la reflexión sobre el conflicto y sus consecuencias y sobre lo que hay detrás de estas representaciones hegemónicas. Aunque Vivir la utopía muestra también esas consecuencias, el discurso que genera parece involucrarse más en la batalla contra el privilegio de las instituciones de las que habla Tagg. Van Dijk constata dicho privilegio de transmitir el discurso verdadero al hablar del acceso a este como una forma de participar en el mismo (Van Dijk 2009). Vivir la utopía trata de controlar el discurso a través de los factores que Van Dijk cree necesarios para el "control de la mente": "el conocimiento personal, y social, las experiencias previas, las opiniones personales y las actitudes, ideologías, valores y normas sociales entre otros factores" (Van Dijk 2009: 32) a fin de un cambio de opinión acerca de la "idea anarquista" (Gamero, 2011) y una validación de este en los "regímenes de verdad".

Las representaciones históricas han estado muy influenciadas por lo que Van Dijk llama “memorias sociales” (1999:29), es decir, conocimientos sobre los hechos socialmente compartidos que ignoran los detalles que se inscriben en cada periodo histórico y que propician estereotipos. Richard Porton advierte sobre la estereotipación cuando habla de la figura del anarquista y lo atribuye a intereses políticos: “Desde que el anarquismo apareció como una filosofía política tangible, los anarquistas han denunciado el ultraje ante los intentos de sus enemigos, en el sentido de convertirlos en estereotipos renegados irracionales y violentos" (Porton, 2001:26). Vivir la utopía huye de estos estereotipos, no obvia la violencia anarquista, pero la contextualiza y muestra todos aquellos ideales de los que otras representaciones prescinde.

Si además tenemos la posibilidad de conocer las motivaciones del realizador para mostrar esta forma de vida del anarquismo, desde la escuela, la cultura, la revolución y los ideales, así como de dar la palabra a aquellos que durante mucho tiempo no la tuvieron, entendemos la importancia de la perspectiva ideológica y del discurso generado.

\section{EL ESPACIO ÉTICO DEL REALIZADOR: LA MIRADA DOCUMENTAL.}

El discurso documental es como dice Gillian Rose "a particular knowledge about the world" (Rose, 2001:136) y esta visión o conocimiento se produce desde la figura del realizador. En el documental "la imagen no sólo ofrece pruebas en beneficio de la argumentación, sino que ofrece testimonio de la política y de la ética de su creador" (Nichols, 1997:117). El film se concibe así como un espacio de representación en el que el realizador muestra su relación con el mundo que representa, el cual estará mediado por la ética del mismo y su presencia. Es mediante la argumentación como percibimos la posición del realizador, la cual se divide en "perspectiva" y "comentario" (Nichols, 1997). La primera se refiere al punto de vista desde el cual se argumenta el documental, 
esta queda implícita en la construcción/montaje del film. El segundo tiene la misma función que la perspectiva, pero es más contundente y explicito con aquello que quiere transmitir al espectador.

Según Nichols, en todo documental existe una relación entre el comentario y la perspectiva, que se visualizan a través de las propiedades formales ${ }^{5}$ (Nichols, 1997) tales como la "subjetividad en el documental", que hace referencia a cómo es argumentado el hecho que se narra, a través de la visión personal del realizador, manifestándose en el discurso a través de la representación. Un ejemplo claro, es el de El edificio de los chilenos, un documental que narra de manera autobiográfica la evolución del "Proyecto hogares". El proyecto, creado en Bélgica y desarrollado en la Habana, está enmarcado políticamente en el exilio de la dictadura chilena. La autora lleva el hilo conductor del documental y todo lo que se muestra en él forma parte de su experiencia o vivencia. La subjetividad del documental también se manifiesta en la elección de lo que es o no mostrado sobre el hecho en sí y la construcción del texto, la designación de actores o entrevistados que siguen una misma línea de pensamiento con el realzador.

"El conocimiento de los hechos" puede limitarse a lo que el realizador conoce o quiere que conozcamos, a través de las entrevistas y el narrador. Aguiló comenta que al reencontrarse de nuevo con la gente que formó parte del proyecto, se encontró discursos muy dispares que eran imposibles enfocar en una misma dirección (Aguiló, 2011).

Si todo el documental se da en relación a la experiencia de vida de la autora, entendemos que la presencia de la Dictadura chilena como contexto histórico en el que se desarrolla el documental, también tiene que ser mostrado desde la perspectiva de Aguiló, sobre lo que dice:

Necesitaba un contexto político para hablar del Proyecto, pero era muy reacia a hablar de la dictadura, en los materiales mismos aparecía justamente esa violencia vivida desde la

\footnotetext{
${ }^{5}$ Estas propiedades formales son designadas por Nichols como "grado de subjetividad, grado de conocimiento, grado de conciencia de sí mismo y grado de comunicatividad"
}

infancia y entendí que yo también fui víctima de la dictadura y lo conté desde la visión de mi infancia (Aguiló, 2011).

"La conciencia de sí mismo" es el punto hasta el cual se hace visible la argumentación en el documental y el conocimiento del espectador ante la existencia de esa argumentación. El edificio de los chilenos no trata de ocultar su argumentación a diferencia de las representaciones históricas que se muestran como "objetivas" borrando los rastros de su montaje, que generalizan el hecho histórico y tratan de homogeneizarlo. Como dice Marrero, a través de Haraway y Latour, hablando de las políticas de representación, una "Cuestión clave: la objetividad no se alcanza simplificando y negando los procesos (de construcción, de escritura), sino reconociendo el carácter artificial y parcial de toda indagación científica y haciendo de ello su piedra angular" (Marrero, 2008: 110). Aguiló justifica abiertamente su presencia diciendo que "en lo que venía después de la historia que era dar cuenta de las consecuencias, me sentía sin la autoridad moral de tratar el tema con los otros si yo no iba primero a ver qué pasa en casa" (Aguiló, 2011)

La última propiedad formal que designa Nichols es "la comunicatividad": lo que el realizador está dispuesto a mostrar o dar a conocer sobre el tema y el modo en el que la información se va dando para mantener la expectación. En El edificio de los chilenos la información se va dando de forma fluida y mantiene la expectación a través de la narración de los hechos, de cómo se va desarrollando el proyecto en relación al proyecto político del MIR. Aguiló comenta que en el momento de llevar a cabo las entrevistas del documental, existieron reticencias por parte de los que vivieron el proyecto a la hora de hablar y de lo que se iba a decir y cómo.

Definitivamente, El edificio de los chilenos no representa la dictadura chilena en sí, sino que va más allá de esta, mostrando las consecuencias sociales de los hechos políticos, tomando como punto de partida la experiencia y narrando en primera persona el hecho. Se trata de una perspectiva enmarcada en lo que muchos llaman "el giro subjetivo" en el documental político (Valenzuela 2011, Rodríguez 2010). Un giro que hace referencia principalmente al documen- 
tal contemporáneo latinoamericano, definido por Ignacio Rodríguez como "un viraje de 180 grados, que desplaza el ángulo de la cámara de los hechos que son objeto de la filmación para incluir al sujeto autor de la película" (2010) en relación a la evolución del documental de Patricio Guzmán ${ }^{6}$. Esta forma documental no se detiene en narrar los hechos históricos, sino en cómo el autor se relaciona con ellos a través de la experiencia. De este modo, no trata de informar al espectador de los sucesos, sino hacerlo reflexionar sobre estos y sus consecuencias.

\section{CONCLUSIONES}

A lo largo del desarrollo de este artículo se ha podido visualizar una serie de estrategias de representación que evidencian la posición del realizador y el discurso político e ideológico inherente en el documental histórico. La intención es la de interpelar la mirada del espectador, a fin de repensarse su posición como tal ante el film. Las estrategias y problemáticas evidenciadas a través del análisis de los tres documentales seleccionados pueden ser extrapoladas, no solo a otros films sino a replantearnos la forma en la que aprendemos y nos relacionamos con el mundo, buscando una posición más crítica.

Si nos posicionamos ante el documental como un espacio de construcción de significados, es imprescindible abordarlo desde una problemática que visibilice las estrategias fílmicas, que nos permita cuestionarnos la articulación de los elementos para comprender qué trata de decirnos realmente el film, qué quiere que aprehendamos de él. Si esta posición nos permite ver más allá de lo visible, entender lo que queda dentro y fuera del campo de visión que nos muestra el realizador y los interese políticos que lo constituyen, los discursos que se dan explícita o implícitamente; si somos capaces de entender que el documental, tal y como Comolli citado por Marrero (2008) dice del cine, "esconde y sustrae más de los que muestra" (p.119), entonces podremos hallar en este un espacio en el cual articular lo que vemos con lo que sabemos dando lugar a la construcción de conocimiento.
Finalmente, en relación a los films analizados es importante destacar en ellos la parcialidad desde la que muestran el mundo histórico. Esa parcialidad es la condición "para que sean oídas las pretensiones (...) sobre las vidas de la gente, de la visión desde un cuerpo complejo, contradictorio, estructurante y estructurado, contra la visión desde arriba, desde ninguna parte, desde la simpleza" (Haraway, 1995:335). Es decir para subvertir la "historia socialmente aceptada", dando acceso al discurso a las miradas parciales extraídas de las representaciones hegemónicas de la "historia", de las que puede surgir ese momento de "verdad".

\section{REFERENCIAS BIBLIOGRÁFICAS}

BRECHT, B. (1984) El compromiso de la literatura y el arte. Barcelona: Ediciones Península.

COMOLLI, J. (2002) Filmar para ver. Escritos de teoría y crítica de cine. Buenos Aires: Ediciones Simurg/Cátedra La Ferla (UBA). En Marrero, I. (2008) Luces y sombras. El compromiso en la etnografía. Revista colombiana de Antropología Vol.44 (1) enero-junio 2008. pp. 95-122.

DIDI-HUBERMAN, G. (2004) Imágenes pese a todo. Memoria visual del Holocausto. Barcelona: Paidos.

ELLSWORTH, E. (2005) Posiciones de la enseñanza: diferencia, pedagogía y el poder de la direccionalidad. Madrid: Ankal.

HARAWAY, D. (1995) Ciencia, cyborgs y mujeres. La reinvención de la naturaleza. Madrid: Cátedra.

MARRERO, I. (2008) Luces y sombras. El compromiso en la etnografía. Revista colombiana de Antropología Vol.44 (1) enero-junio 2008. pp. 95-122.

NICHOLS, B. (1997) La representación de la realidad. Barcelona: Paidos.

PORTON, R. (2001) Cine y anarquismo. La utopía anarquista en las imágenes. Barcelona: Gedisa.

RANCIÈRE, J. (2010) El espectador emancipado. Castellón: Ellago Ensayo.

ROSE, G. (2001) Visual Methodologies. An introduction to the Interpretation of Visual Materials. Londres: SAGE.

SÁNCHEZ DE SERDIO, A. (2010) Miradas cruzadas: visualidad/representación pedagógica/política. En Alberto Altés (ed) Dissensus. Arquitectura, política, cine (en prensa).

STEYERL, H (2005) La articulación de la protesta Brumaria, 5.

TAGG, J. (2005) El peso de la representación. Barcelona: Gustavo Gil.

VAN DIJK, T (2009) Discurso y poder. Gedisa: Barcelona.

${ }^{6}$ Reconocido director- realizador documental, chileno. 


\section{REFERENCIAS INTERNET}

AGUILÓ, M. (2011) Coloquio tras la proyección de El edificio de los chilenos. Mediado por Tabernero, S. En Madrid, Casa América. Marzo 2011. [En línea] Recuperada el 10 de Junio de 2011 de

http://www.casamerica.es/cine/el-edificio-de-los-chilenos

FAROCKI, H. (2009) Entrevista con motivo del III Premio de Cine de ensayo. Realizada por Ledo, R. en Universitat Autónoma de Barcelona. Marzo 2009. [en línea] Recuperado el 25 de Mayo de 2011 de http://www.youtube.com/watch?v=4GA1ZM9ZwoQ (Primera parte).

http://www.youtube.com/watch?v=VODWiQAHAFM\&feature=related (Segunda Parte).

RODRÍGUEZ, I. (2010) Giro subjetivo en el documental político latinoamericano: el caso de Patricio Guzmán Revista Imagofagia [en línea] Asociación Argentina de Estudios de Cine y Audiovisual (ASAECA). Recuperado el 6 de Mayo de 2011 de:

http://www.asaeca.org/imagofagia/sitio/index.php?option=com_content \&view=article\&id=96\%3Agiro-subjetivo-en-el-documental-politico-latinoamericano-el-caso-de-patricio-guzman \&catid=35\& Itemid=64

STEYERL, H (2009) La verdad desecha. Productivismo y Factografía. Instituto Europeo para políticas culturales progresivas [en línea] Recuperado el 12 de Abril de 2011 de http://eipcp.net/transversal/0910/steyerl/es

VALENZUELA, V. (2011) Giro Subjetivo en el documental latino americano De la cámara-puño al sujeto-cámara. La fuga [en línea] . Dossier Interiores: cine y subjetividad Abril 2011. Recuperado el 20 de Mayo de 2011 de

http://www.lafuga.cl/giro-subjetivo-en-el-documental-latinoamericano/439

VAN DIJK, T (1999) Análisis crítico del discurso. Antrophos: Barcelona, [en línea] (186) pp. 23-36. Recuperado el 17 de Abril de 2011 de http://www. discursos.org/oldarticles/El\%20an\%E1lisis\%20cr\%EDtico\%20del\%20discurso.pdf

\section{OTRAS REFERENCIAS}

GAMERO, J.A. (2011). Comunicación personal vía e-mail el 20 de Junio de 2011

\section{FILMOGRAFÍA}

AGUILÓ, M. (2010) El edificio de los chilenos. Producción de ICAIC. Chile-Francia-Cuba.

FAROCKI, H. (2007) Respite. Producido por Harun Farocki.

GAMERO, J.A. (1997) Vivir la utopía. Producido por TVE- Catalunya y ARTE (Francia).

\section{NOTA:}

Basado en la tesina "Estrategias documentales en la representación del hecho histórico como generadoras de discurso político e ideológico. A partir de tres ejemplos fílmicos". Presentada para el programa de Master de Artes visuales y educación: un enfoque construccionista en 2010/2011 en la Universidad de Barcelona. Tutorizada por: Aida Sánchez de Serdio.

\section{AGRADECIMIENTOS:}

a Aida Sánchez de Serdio por su acompañamiento y por toda su ayuda y dedicación como tutora. 